\title{
Empleo
}

\section{de Aceite}

\section{Quemado para}

Mejorar las

\section{Propiedades}

\section{Mecánicas}

\section{de Bases}

\section{y Subbases}

\section{Granulares}

- Ingeniero Civil Universidad de Los Andes. Magister en Ingenieria Civil - Geotecnia Universidad de Los Andes. Jefe del Area de Geotecnia de la Universidad Militar "Nueva Granada".

\section{RESUMEN}

D este artículo se describe la realización De un estudio experimental de laboratorio para la viabilidad del empleo de aceite quemado producido por el parque automotor de las grandes metrópolis, en la mejora de las propiedades mecánicas de las bases y subbases granulares empleadas para la construcción de una estructura de pavimentos, mediante la ejecución de los ensayos de proctor estándar, proctor modificado y C.B.R. de laboratorio.

El porcentaje de aceite quemado introducido en la ejecución de los ensayos de C.B.R., es determinado como reemplazo total o parcial de los porcentajes de humedad óptima de agua $\mathrm{y}$ aceite encontrados en los ensayos proctor. 
Los principales resulrados obtenidos en la investigación corresponden a la determinación de los porcentajes óptimos de agua, aceite, y aceite con agua, que se deben emplear para alcanzar incrementos en la resistencia mecánica y en la densidad de los materiales de base y subbase granular.

\section{PALABRASCLAVE}

C.B.R., ensayo de compactación (proctor estándar y modificadol, aceire, bases y subbases granulares, concenido de humedad óptima y estructura de pavimento.

\section{METODOLOGIA}

Para el desarrollo del estudio experimental en cuestión. se realizaron las siguientes actividades:

1. Decerminación de las curvas granulomécricas para bases y subbases granulares a emplear. (Se utilizaron las curvas granulométricas A.B.C y D para bases y las curvas granulométricas $A, B$ y $C$ para subbases, de acuerdo con las especificadas del Instituto de Desarrollo Urbano IDU.)

2. Caracterización del material granular (Determinación del concerido de materia orgánica, humedad natural, límites de Atterberg. desgaste de la máquina de los Ángeles, equivalente de arena etc.)

3. Caracterización del aceite quemado (viscosidad y G.S.)

4. Ejecución de los ensayos de compacración proctor eständar y proctor modificado, para determinar la humedad óptima de agua, aceice y combinación de agua con aceite, en los materiales granulares empleados.

5. Ejecución de los ensayos C.B.R. de laborarorio para los porcentajes de humedad óptima para agua, aceite y combinación de las clos.
6. Comparación y análisis de los resultados para los ensayos de proctor estándar. proctor modificado y C.B.R. de laboratorio.

\section{CONCLUSIONES}

Con los resultados obcenidos en los ensayos proctor estándar. proctor modificado y C.B.R. de laboratorio, se pudo concluir la viabilidad del empleo de aceite quemado para me. jorar la resistencia mecánica y densidad máxima de algunas bases y subbases granulares. de acuerdo con las especificaciones gramulométricas del Instituto de Desarrollo Urbano.

Teniendo en cuenta la conclusión anterior, a continuación, se extraen los resultados obtenidos para las bases granulares con adición roral o parcial de aceite quemado en los ensayos de proctor estándar (figura No. 1). procror modificado (figura No. 2) y C.B.R. de laboratorio (figura No. 3), concluyendo con base en la muestra parrón (humedad óptima con $100 \%$ de agua) lo siguiente:

- De los ensayos procror esrándar y modificado. la densidad máxima presenta incremento para reemplazo total o parcial de aceite por agua, excepto рага la base tipo $C$, con una combinación de $25 \%$ de agua y $75 \%$ de aceite y un decremento del $0.3 \%$.

- El mayor incremento de la densidad máxi. ma en los ensayos de compactación (proccor estándar y modificado) fue de $7.5 \%$ para la base cipo $C$, con una combinación de $75 \%$ de agua y $25 \%$ de aceite.

- Los incrementos de densidad máxima para el ensayo de proctor estándar oscilan entre $0.8 \%$ y $7.5 \%$, y $0.5 \%$ y $7.0 \%$ para el ensayo de proctor modificado.

- Los mayores incremencos de la densidad para los ensayos de proctor estándar y de proctor 
PROCTOR ESTÁNDAR PARA BASES

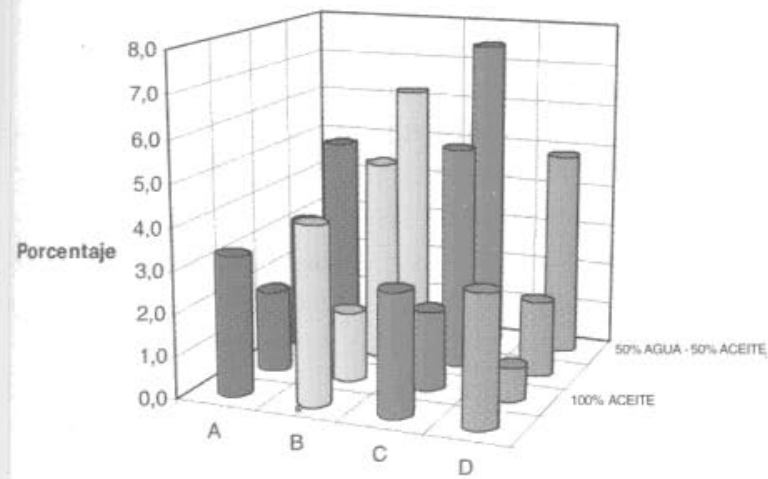

Tipo de Granulometria

FGUPA No. 1

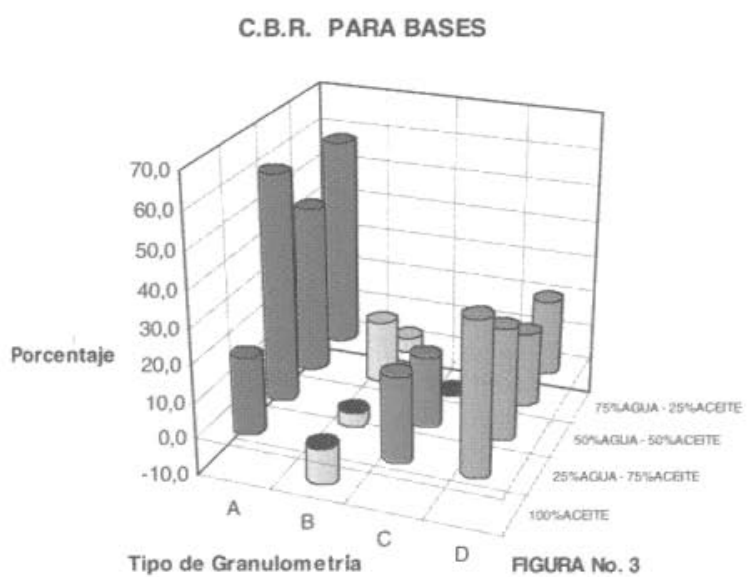

\section{PROCTOR MODIFICADO PARA SUBBASES}

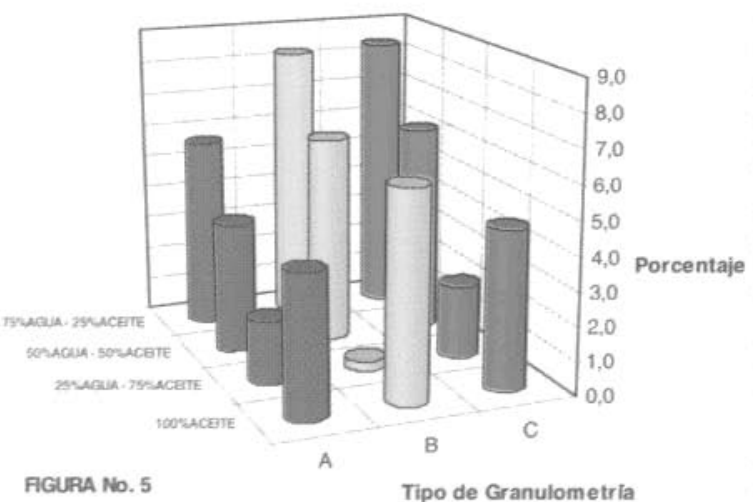

PROCTOR MODIFICADO PARA BASES

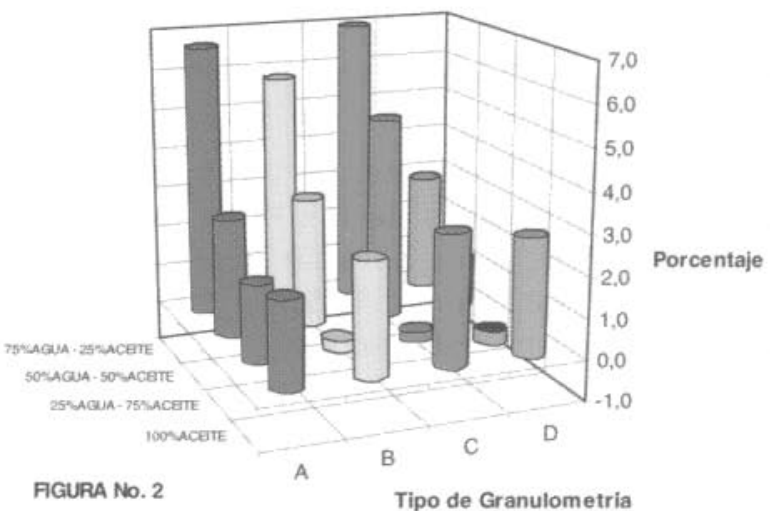

PROCTOR ESTÁNDAR PARA SUBBASES

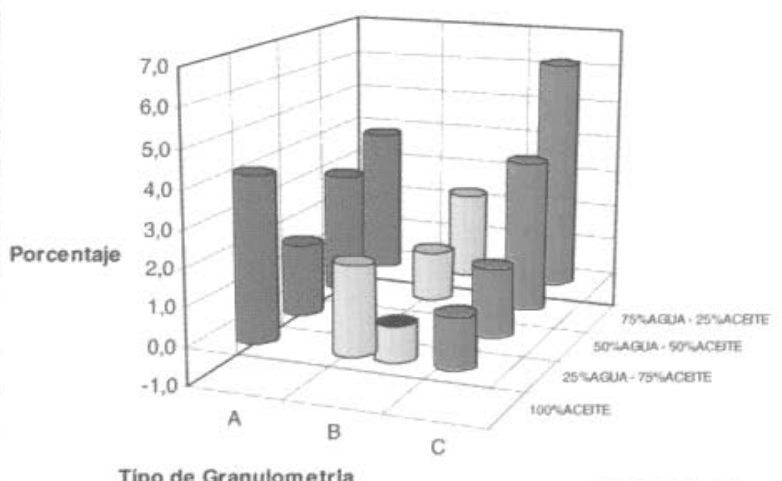

FGURA No. 4
C.B.R. PARA SUBBASES

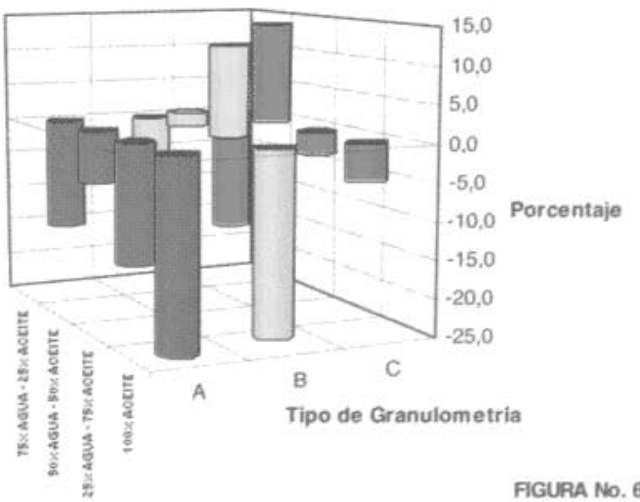


modificado se encuentran para las combinaciones de $75 \%$ de agua y $25 \%$ de aceite y para $50 \%$ de agua y $50 \%$ de aceite, respectivamente.

- Para la resistencia mecánica calculada a partir de los ensayos de C.B.R. de laboratorio. se determinó que para las bases tipo $B$, en combinaciones de $25 \%, 50 \%$ y $100 \%$ de aceite. existe un descenso de la resistencia mecánica, así como para la base tipo $\mathrm{C}$ en la combinación 50\% de agua y 50\% de aceite.

- La resistencia mecánica máxima se encuentra en las muestras de base tipo A, con incrementos entre $47 \%$ y $62 \%$.

Mientras que para las subbases granulares con adición total o parcial de aceite quemado en los ensayos de proctor estándar (figura No.4), proctor modificado (figura No. 5) y C.B.R. de laboratorio (figura No. 6), las conclusiones establecidas con base en la muestra patrón (Humedad óptima con 100\% de agua) fueron:

- El mayor incremento de la densidad máxima en el ensayo proctor estándar es $6 \%$, en la subbase $C$ y con una combinación de $75 \%$ de agua y $25 \%$ de aceite.

- Los incrementos de densidad mảxima para el ensayo de proctor estándar oscilan entre
$1.25 \%$ y $6.0 \%$ y entre $0.5 \%$ y $8.25 \%$ para el ensayo de proccor modificado.

- Los mayores incrementos de densidad máxima para el ensayo de proctor estándar y proctor modificado se encuentran en las combinaciones de $75 \%$ de agua y $25 \%$ de aceite y $50 \%$ de agua y $50 \%$ de aceite, respectivamente.

- Рara la resistencia mecánica calculada con el ensayo de C.B.R. de laboratorio, la subbase tipo $A$, en las diferentes combinaciones de agua con aceite, siempre presentó un descenso en su resistencia, las cuales Ilegaron hasta un 23\% con respecto a la muestra patrón.

\section{BIBLIOGRAFIA}

- REYES Ortiz. Oscar Javier. Uso de aceite quemado para estabilizar bases y subbases granulares. Uniandes. 1997.

- REYES Lizcano, Freddy. Diseño de pavinentos por métodos racionales. Uniandes. 1997.

- PORRAS. Myriam y Yesi Rodrighez. Uso de aceite quemado para mejorar las propiedades mecánicas de bases y subbases granulares. Universidad Militar "Nueva Granada". 2000.

- Instituto de Desarrollo Urbano. Éspecificaciones técricas de construcción. IDU. 1998.

- Instituto Nacional de Vías. Normas Técnicas INVIAS. Edirorial Escuela Colombiana de Ingeniería. 1998.

- FERNÁNDEZ, Carlos. Mejolamienco y estabilización de suelos. Editorial Limusa 1982. 